biopsy specimens from our patient closely resemble those described in the case reported by Castaigne et al, we are not convinced that these cells were part of a truly neoplastic lesion in our case. There was a cyst present in one affected cerebellar hemisphere but no obvious tumour mass was detectable at surgery or necropsy. We therefore regard the bizarre astrocytes, a few of which clearly contained JC virus nucleic acid, as falling at the extreme end of the well recognised spectrum of pleomorphic astrocytic change seen in PML.

The cause of our patient's sclerosing cholangitis was unclear. Sclerosing and ascending bacterial cholangitis have been associated with campylobacter and cryptosporidial infection in patients with primary immune deficiencies. ${ }^{9}$ It has been suggestd that bacterial overgrowth in the upper small intestine may be an important predisposing factor in these cases. Interestingly, primary sclerosing cholangitis in immunocompetent subjects has recently been associated with significantly increased titres of serum antibodies to JC and or BK viruses. ${ }^{10}$ This raises the possibility that reactivation of polyoma virus may have been responsible for both PML and sclerosing cholangitis in our patient.

We thank Professor John Newsome-Davis FRS for permission to report this case. Drs Anne Simmonds and Paul Holloway kindly carried out the biochemical investigations. We thank Lynda Beckley for typing the manuscript.

1 Knight A, O'Brien P, Osoba D. "Spontaneous" progressive multifocal leucoencephalopathy-Immunological aspects. Ann Int Med 1972;77:229-33.

2 Wallace DC, Singh G, Lott MT, et al. Mitochondrial DNA mutation associated with Leber's hereditary optic neuropathy. Science 1988;242:1427-30.

3 Zegers BJM, Stoop JW. Metabolic causes of immunodeficiency mechanisms and treatment. In: Webster ADB, ed. Immunodeficiency and disease. Lancaster: MTP Press, Immunodeficiency

4 Brooks EG, Schmalstieg FC, Wirt DP, et al. A novel $\mathrm{X}$-linked combined immunodeficiency disease. $\mathcal{f}$ Clin Invest 1990;86:1623-31.

5 Alarcon B, Terhost C, Arnaiz-Villena A, et al. Congenital T cell receptor immunodeficiencies in man. Immun Rev 1990;2:1-16.

6 Mori M, Kurate H, Tajuina M, et al. JC virus detection by in-situ hybridization in brain tissue from elderly patients. Ann Neurol 1991;29:428-32.

7 Portegies P, Algra PR, Hollak CEM, et al. Response to cytarabine in progressive multifocal leucoencephalopathy in AIDS. Lancet 1991;337:680-1.

8 Castaigne P, Rondot P, Escourolle R, et al. Leucoencephalopathie multifocale progressive et "gliomes" multiples. Rev pathie multifocale progressive et

9 Webster ADB. Immunodeficiency and the gut. Clin Gastroenterol 1987;1:547-65.

10 Snook JD. Autoimmunity in the pathogenesis of ulcerative colitis. Thesis. University of Oxford, 1991:119-26.

\title{
Isolation of Legionella pneumophila serogroup 14 from a human source
}

\author{
M Castellani Pastoris, C Berchicci, G Pallonari
}

Bacteriology and

Medical Mycology, Istituto Superiore di Sanità 00161 Rome, Italy M Castellani Pastoris C Berchicci

Laboratory of Microbiology, Ospedale S Camillo, Rome, Italy G Pallonari

Correspondence to: Dr M Castellani Pastoris Accepted for publication 1 November 1991

\begin{abstract}
A strain of Legionella pneumophila serogroup 14 was isolated during a retrospective study, after death from the sputum of a patient who had had acute leukaemia and pneumonia. This is the third strain of that serogroup to be isolated from a human source. This event emphasises the importance of performing culture as well as serological tests, so as to detect cases of legionellosis caused by strains which rarely cause fatal clinical illness.
\end{abstract}

Since 1976, when a "new" micro-organism, Legionella pneumophila, was first isolated, ${ }^{1} 14$ serogroups of this species have been described. $^{24-7}$ All serogroups are potential pathogens for humans, but some seem to cause illness more frequently than others.

To our knowledge, only two human isolates of $L$ pneumophila serogroup 14 have been described $^{2}$ : one was isolated at the Minnesota Department of Health, Minneapolis, USA (strain 1169-MN-H); and the other was iso- lated at Ruchill Hospital, Glasgow, Scotland (strain 1586-SCT-H).

\section{Case report}

A 28 year old man in relapse of acute leukaemia after autologous bone marrow transplantation a year previously was admitted to hospital with a 10 day history of fever, followed by diarrhoea, epigastric pain, earache, and a white cell count of $7 \times 10^{8} / 1$. A chest $x$-ray picture was unhelpful. Laboratory examinations showed antibodies to hepatitis viruses $\mathrm{A}$ and $\mathrm{B}$. The patient was initially treated with imipenem, and thereafter with teicoplanin and ceftazidime. After a positive blood culture for Candida pseudotropicalis vancomycin and amphotericin were added. He developed a scantily productive cough. Ceftazidime was replaced with piperacillin. A chest $x$-ray picture four days later showed the presence of confluent densities in the middle right and lower lobes and the left parahilar area. Antibiotic treatment was changed to imipenem and cotrimoxazole. Dyspnoea and peripheral cyanosis appeared the following day, and the 
patient died a day later. Routine cultures of an expectorate sample taken a week before he died yielded Candida sp. but a blood culture performed the day before he died was negative.

Attempts at culturing legionellae from this patient during a retrospective study on inpatients with pneumonia yielded a Legionella from the expectorate sample. This strain was first tested against an $L$ pneumophila monoclonal antibody (Diagnostics Pasteur, France) and monovalent antisera to $L$ pneumophila serogroups 1-10. It seemed to react with the monoclonal antibody and the serogroup 10 antisera. The strain was subsequently examined using antisera against $L$ pneumophila serogroups 1-14 and 34 other species at the Public Health Laboratory Service Legionella Reference Unit, Colindale, London. It reacted strongly with antiserum to $L$ pneumophila serogroup 14 and weakly with antisera against serogroups 8 and 10; no reaction was observed with antisera to the other Legionella species. The specificity of the reaction with serogroup 14 was confirmed using absorbed $L$ pneumophila serogroup 14 specific antiserum. The strain gave positive results in tests for catalase, hippurate hydrolysis, gelatin liquefaction, browning on tyrosine containing media and $\beta$-lactamase production, and negative results for oxidase, autofluorescence, and bromocresol-purple tests. ${ }^{8}$

Blood for serology for Legionella infection was not available.

\section{Discussion}

$L$ pneumophila subgroup 14 is a rare cause of clinical illness in man. The infection seems likely to have been acquired nosocomially. Studies on the water supply on the ward where the patient was staying yielded only $L$ pneumophila serogroup 3. However, this could have been due to the fact that an autonomous electric heater had been installed in the bathroom of the ward, obviating the need to use the central hot water supply, and the shower and taps had been replaced before the water samples were collected.

To our knowledge, the isolate described here (called strain Roma 9/1539) is the third $L$ pneumophila serogroup 14 strain to be isolated from the human source. The possibility that it may represent a contaminant resulting from specimen collection procedures is highly unlikely, because the expectorate sample examined was the only one which yielded legionellae among a group of 80 collected in the same hospital during a one month period.

Reagents for detection of legionellae in pathological material by immunofluorescence or for antibody testing are not always available in the laboratory for Legionella species or serogroups that are rare causes of infection. Moreover, patients with severe legionellosis, who are often immunocompromised, are usually serologically negative at an early stage of the illness. The need to perform culture as well as serological tests is emphasised by the results decribed here. This case was only detected after the patient had died because Legionella was not suspected and would have been missed if sputum culture specifically for Legionella species had not been performed as part of a retrospective investigation on patients with pneumonia.

We are grateful to TG Harrison (Legionella Reference Unit, Central Public Health Laboratory, Colindale, London) for examining and typing our strain.

1 McDade JE, Shepard CC, Fraser DW, Tsai TR, Redus MA, Dowdle WR. Legionnaires' disease: isolation of a bacterium and demonstration of its role in respiratory disease. N Engl F Med 1977;297:1197-203.

2 Benson RF, Thacker WL, Wilkinson HW, Fallon RI, Brenner DJ. Legionella pneumophila serogroup 14 isolated from patients with fatal pneumonia. 7 Clin Microbiol 1988;26:382.

3 Lindquist DS, Nygaard G, Thacker WL, Benson RF Brenner DJ, Wilkinson HW. Thirteenth serogroup of Brenner DJ, Wilkinson HW. Thirteenth serogroup of pneumonia. $¥$ Clin Microbiol 1988;26:586-7.

4 Meenhorst PL, Reingold AL, Groothuis DG, et al. Waterrelated nosocomial pneumonia caused by Legionella pneumophila serogroups 1 and 10 . $\mathcal{f}$ Infect Dis 1985;152:356-64.

5 Thacker WL, Benson RF, Wilkinson HW, et al. 11th Serogroup of Legionella pneumophila isolated from patient with fatal pneumonia. $\mathcal{f}$ Clin Microbiol 1986;23:1146-7.

6 Thacker WL, Plikaytis BB, Wilkinson HW. Identification of 22 Legionella species and 33 serogroups with the slide agglutination test. $¥$ Clin Microbiol 1985;21:779-82.

7 Thacker WL, Wilkinson HW, Benson RF, Brenner DJ. Legionella pneumophila serogroup 12 isolated from human and environmental sources. $f$ Clin Microbiol $1987 ; 25: 569-70$.

8 Harrison TG, Taylor AG. Phenotypic characteristics of legionellae. In: Harrison TG, Taylor AG, eds. A laboratory manual for Legionella. Chichester: John Wiley \& Sons Ltd, 1988:45-56. 